\title{
Contested Histories: De-mythologising the Early History of Modern British Computing
}

\author{
David Anderson \\ University of Portsmouth, "The Newmanry", \\ 36-40 Middle Street, Portsmouth, Hants, United Kindom, PO5 4BT
}

\begin{abstract}
A challenge is presented to the usual account of the development of the Manchester Baby which focuses on the contribution made to the project by the topologist M.H.A. (Max) Newman and other members of the Dept. of Mathematics. Based on an extensive re-examination of the primary source material, it is suggested that a very much more significant role was played by mathematicians than is allowed for in the dominant discourse. It is shown that there was a single computer-building project at Manchester in the years immediately following World War II and that it was conceived, led, funded, supplied and staffed by Newman who was supported throughout by his long-time friend P.M.S. (Patrick) Blackett. In the course of the paper three persistent myths, which lend support to the dominant narrative, are identified and debunked.
\end{abstract}

Keywords: Manchester Baby, SSEM, Max Newman, Patrick Blackett, British Computing, Historiography.

\section{Introduction}

It is almost exactly 60 years since the world's first digital electronic stored-program computer - the Manchester Baby or SSEM -ran for the first time. The story of how the machine came to be developed by Prof F.C. Williams and Mr. T. Kilburn from the Dept. of Electro-Technics, without any significant external assistance is well known and has come, within the sub-discipline of the history of computing, to represent a dominant historical narrative.

I will offer a challenge to the usual account of the development of the Manchester Baby. In doing so, I will focus on the contribution made to the project by the topologist M.H.A. (Max) Newman and other members of the Dept. of Mathematics. Based on an extensive reexamination of the primary source material, I will suggest that a very much more significant role was played by mathematicians than is allowed for in the dominant discourse. In short, I will show that there was a single computer-building project at Manchester in the years immediately following World War II and that it was conceived, led, funded, supplied and staffed by Newman who was supported throughout by his long-time friend P.M.S. (Patrick) Blackett. I will identify and debunk three persistent myths, which lend support to the dominant narrative. 


\section{A Note on Motivation}

It is perhaps worth saying explicitly that my purpose is not to argue that historians of computing should, in their accounts of the period, replace heroic engineering pioneers with heroic mathematicians. The principal problem with the conventional account is not that it allocates credit inappropriately but that in so doing it helps obscure much more interesting historical questions concerning the role played by the government in fostering and directing technological innovation and development in Britain both during the second world war and in the immediate post-war period. 1 The historical reevaluation of the development of the Manchester Baby which I present should not be understood as an end in itself nor, primarily, as a contribution to a credit dispute but rather as a necessary clearing of the ground so that historians of technology can engage with topics of greater historical significance.

\section{M.H.A. Newman}

Despite having received very little attention from historians of computing, it is no exaggeration to say that Max Newman was one of the most significant figures in the early history of British computing. His direct influence was exerted over more than a decade beginning at Cambridge before the Second World War, continuing at Bletchley Park during hostilities, and finishing in the peace-time setting of Manchester in the mid-late 1940s.

Newman's deeply-ingrained habit of understating his own contribution and preference for stressing the accomplishments of others goes some way towards explaining why historians of computing have generally paid only superficial attention to this remarkable man who is, in consequence, principally remembered today for his work as a mathematician and topologist.

\section{Turing and the Roots of Modern Computing}

Modern computing is often said to have originated with A.M. (Alan) Turing. If so then its roots can be traced back through Newman to a talk given by David Hilbert at the Sorbonne on the morning of the 8th August 1900 in which he proposed twentythree "future problems" for mathematics research in the 20th century. The tenth of Hilbert's questions led directly to Hilbert and Ackerman's 1928 formulation of the Entscheidungsproblem [1], which Hilbert considered to be "the central problem of mathematical logic" [2]. The essence of the question was: could there exist, at least in principle, a definite method or process involving a finite number of steps, by which the validity of any given first-order logic statement might be decided?

Turing seems first to have encountered the Entscheidungsproblem around the Spring of 1935 when he was a student on Newman's Part III course on the foundations of mathematics [3]. Solving the Entscheidungsproblem rigorously was entirely dependent on the extent to which a formalisation of the notion of "process" could be devised and it was this task which Turing, acting on a suggestion of Newman's, accomplished so dramatically: 
In the middle of April 1936, Turing presented Newman with a draft of his breathtakingly original answer to the Entscheidungsproblem [4]. At the heart of Turing's paper was an idealised description of a person carrying out numerical computation which, following Church, we have come to call a "Turing machine". All modern computers are instantiations of Turing machines in consequence of which Turing's paper is often claimed to be the single most important in the history of computing.

From the moment Newman saw Turing's solution he took him under his wing. Newman canvassed successfully for "On Computable Numbers" to be published by the London Mathematical Society and, simultaneously, enlisting Alonzo Church's assistance in arranging for Turing to spend some time studying in Princeton.

Cambridge in the late thirties and early forties seems to have provided particularly fertile soil for computing pioneers and Newman played a part in the education of most of them. In addition to Alan Turing and his exact contemporary Maurice Wilkes, other students of Newman's included Tom Kilburn, Geoff Tootill and David Rees.

\section{Bletchley Park}

On the $16^{\text {th }}$ March 1939, as war was breaking out across Europe, Newman was awarded a fellowship of the Royal Society. However, there was little opportunity to use this as a springboard for further work in mathematics. The outbreak of hostilities took one colleague after another out of academic life into war work. Newman grew increasingly disillusioned with life at Cambridge and at the suggestion of Blackett, he accepted a post at Bletchley Park. Neither of them could have had the least inkling that Newman had embarked on a course which was to completely alter the future direction of his career. Max was initially appointed as a cryptanalyst as part of John Tiltman's group. The type of transmission which attracted the greatest interest was known as 'Tunny' and carried messages between the very highest ranks of the German command. Manual methods utilising statistical techniques had been devised for breaking into the code but the sheer volume of traffic being intercepted was beginning to overwhelm the human resources available.

Newman believed it was possible, in principle, to mechanise the attack on Tunny and successfully lobbied to test his conviction by developing an electro-mechanical code-breaking machine which came to be known as the "Heath Robinson".

The Heath Robinson proved fairly unreliable but the results it achieved were sufficiently impressive for approval to be given to develop a more sophisticated machine - the Colossus. A great deal has been written about this apparatus now widely recognised as the world's first digital electronic computing machine. In the current context, it should be sufficient to note that had Newman done nothing else in his career he would have been assured of a place among the most important figures in early British computing simply by virtue of having led the development of this machine.

\section{Manchester and the Birth of Modern Computing}

The Colossus was to have a profound effect on Newman's future career. He saw at once, as few others did, the impact that computing would come to have on mathematics 
and resolved to establish a computer-building project as soon as the war was over. The mathematics department at Cambridge was not the right environment in which Newman's new ambition could be pursued and he began to look around for a more favourable setting. With the help and encouragement of Blackett, Max was appointed to the Fielden Chair of Pure Mathematics at Manchester University. Newman had two clear goals in mind: to establish a first rate department which could stand comparison with the best in the country and to build a computer. At Bletchley, Newman was surrounded by people who could help him achieve both objectives.

In a clear declaration of intent, Newman brought with him from Bletchley Park, I.J. (Jack) Good and David Rees11. Both these Cambridge mathematicians had served in the Newmanry and in addition to having impeccable mathematical qualifications both had a familiarity with the Colossus that would be invaluable for the work that Newman had in mind. With Blackett's assistance a substantial grant was secured from the Royal Society explicitly for the purpose of developing a computer - the first such award ever made and a huge triumph for Manchester.

The only piece of the puzzle that was missing was a lead engineer. Newman had, before submitting his funding application to the Royal Society, secured limited support from Prof Willis Jackson who was the head of Manchester's department of Electro-Technics. Jackson agreed that when Newman was able to secure the services of a full-time engineer he could be attached to Jackson's department. It is apparent from the available documentary evidence that Newman felt able to take Jackson into his confidence to a much greater extent than is generally supposed. The work carried out at Bletchley Park during the Second World War was classified well beyond Top Secret and Newman was very well aware of the restrictions imposed on him by the Official Secrets Act. The very great extent to which the secrets of Bletchley Park were preserved has often been remarked upon, indeed Churchill described the Bletchley code breakers as his "geese that laid the golden eggs and never cackled". Within the History of Computing it is usually claimed that the Colossus could have had no impact on the development of civilian computing because even the mere fact of its existence was kept completely secret until the mid-1970s. I have elsewhere called this claim the myth of secrecy [5].

In fact, Newman not only revealed the existence of Colossus to Willis Jackson but actually took him, during the Summer of 1945, to see a number of Colossi in situ at Bletchley Park and obtained advice from him on which components of the machines could be re-used in the construction of a computer at Manchester. Acting directly on Jackson's advice Newman made arrangements for "...the material of two complete Colossi"[6] to be transported from Bletchley to Manchester - the transfer taking place later the same year. The significance of Jackson's visit to Bletchley is enormous since it could not have taken place without security clearance having been obtained at the highest level. Jackson's presence in Bletchley during 1945 is a clear indication of government support for Newman's computer-building project and constitutes conclusive disproof of the claim that Colossus could not have had an impact on the development of peacetime computing because of the secrecy surrounding its existence. In fact there is also some documentary evidence supporting the claim that Newman discussed the Colossus with John von Neumann and with F.C. Williams. There are also clues in the Royal Society papers concerning Newman's funding application that his involvement with computing during the war was known to the funding committee. 
Jackson's support for Newman's project was valuable but stopped short of providing him with the engineering expertise he required to actually construct a computer. Newman was not the only person looking for a top-flight engineer; the National Physical Laboratory(NPL), were also planning to build a computer and "Good circuit" men, as Newman wrote to von Neumann, were "both rare and not procurable when found" [7]

F.C. (Freddie) Williams found himself at the end of the war in the fortunate position of being a man greatly in demand. Williams had been a lecturer at Manchester before the war and had spent the war years working at the Telecommunications Research Establishment helping develop Radar and leading a small trouble-shooting team. By the end of hostilities Williams was widely recognised as one of the best electrical engineers around and he was actively courted by NPL and by Newman. In the end Williams choice was relatively easy to make. NPL's proposal was that Williams should work on Turing's ACE design and not only afforded Williams less freedom to develop his own ideas than he wanted but also compelled him to work with Turing -a prospect Williams did not relish. Newman and Manchester were able to offer Williams the prospect of a chair in Electro-Technics On his appointment, Williams brought with him, Tom Kilburn, newly re-cast as a Ph.D. student funded by TRE. Having secured the support of the university, obtained funding from the Royal Society and assembled a first-rate team of mathematicians and engineers, all the elements of Newman's computer-building plan were in place. Adopting the same approach as he had used at Bletchley Park, Newman set his people loose on the detailed work while he concentrated on orchestrating the endeavour. The result was, once again, success beyond all expectation. By the middle of 1948 the Manchester Baby was up and running and although it was little more than a proof of concept it was still the world's first working digital electronic stored program computer. Through the agency of Patrick Blackett, Sir Ben Lockspeiser was shown the Baby and government support for the manufacture by Ferranti of a production version of the machine was quickly secured.

\section{Contested History}

The account which I have given of the development of the Manchester Baby and the role played in it by Newman represents a very radical departure from the conventional history of the project. It is appropriate now to consider in some detail the principal ways in which the dominant narrative differs from the interpretation which I have presented.

The earliest history of the development of the Baby was written by S.H. (Simon) Lavington according to whom there were, in fact, two distinct and separate Manchester projects to build a stored program digital computer, one led by Williams and the other by Newman. On this account Williams' project is presented as a triumph from which the engineers emerge as heroes whereas, by contrast, Newman's project is characterized as a failure and the mathematicians, in so far as they are mentioned at all, are portrayed as marginal figures.

This "two project" account has very general currency and forms part of a wider professional mythology within which the engineering or practical perspective is privileged 
while the mathematical or theoretical point of view is almost entirely excluded. Lavington's assertion that the mathematicians took no active part in the design process sounds plausible. However the claim of non-involvement is more complex than may, at first, be apparent and is entirely dependent on what precisely is meant by 'active' and 'design'. Williams' personal recollection after the event that neither he nor Kilburn knew the first thing about computers until 1947 when Newman and Turing explained to them how computers work [8] is prima facie evidence, coming from an engineering source, of at least one active contribution made by the mathematicians. Further evidence of collaboration is to be found in the contemporaneous records kept by Jack Good, one of Newman's mathematicians, which show a free exchange of ideas and documents passing between the engineers and the mathematicians. Good also recalled having had a hand in the general theoretical education of the engineers. According to Donald Michie, Newman delivered, at Manchester in the immediate post war period, a series of lectures on computing which helped shape the understanding of the engineers and constituted part of their computing education [9].

Moving outside the immediate Manchester circle, Turing and Wilkinson delivered a series of lectures on the design of the ACE which took place at the Ministry of Supply's London Headquarters from late 1946 to early 1947. Kilburn attended these lectures [10]. It is clear at least that Newman, Turing and Good were, contrary to the impression which may have been left by Lavington, active in disseminating ideas on computer design and in educating engineers to the point where they could engage constructively with the problem of building a computer. The characterization of the mathematicians as passive enthusiasts runs counter to the available evidence.

Of course, it is one thing to note that mathematicians within Manchester and more widely were active in stimulating an interest in computing per se but quite another to show that they had a tangible effect on the actual design of the Baby. However, there is no reason why anyone should have ever expected mathematicians to be making that kind of contribution. It is one of the shortcomings of Lavington's account that it suggests active involvement by mathematicians in the detailed circuit design of the Manchester Baby is a pre-requisite for their being full partners in the project. This is, of course, very much to see the world from the perspective of the drawing board or the soldering iron and it is important to recognize that what counts as activity is critically dependent on one's point of view. At Bletchley Park, Newman, along with others, took great care to explain to Flowers and the Post Office engineers precisely what was required of the machine which needed to be produced. This would have involved giving an explanation of enough by way of general principle as would be needed to enable the engineers make progress. In the case of Colossus, it would also have been necessary to provide detailed explanation of the precise statistical techniques which the machine was to employ and an explanation of the sort of changes in German encryption techniques to which the machine might need to respond during its lifetime. Clearly, it was only when the engineers understood exactly what was required of them that they would have been in a position to exercise their particular professional skills. In spite of the general direction in which the flow of information moved in this preconstruction phase, it would be a mistake to characterize the early development of the Colossus as involving active mathematicians and passive engineers. It would be more accurate to think in terms of a joint endeavour involving active dialogue. The fact that the skills of a number of different professions had to be brought to bear on the 
problem is no demonstration that there were two different computing projects at Bletchley Park only one of which, the Flowers project, led to the successful development of a machine. Nor, it must be said, has anyone ever suggested otherwise. Similarly, even were it the case that the Manchester mathematicians had absolutely no involvement in the detailed circuit design of the Baby we would require more evidence to show that there were two different computer building projects in existence only one of which was a success. If Williams had been engaged in an independent attempt to build a computer it should be possible to find confirmation in the form of contemporaneous documents. The civilian effort to develop a computer (or computers) at Manchester was not subject to official secrecy restrictions and there is no reason to suppose that evidence would be hard to find. There are plenty of documents confirming Newman's activity. We can trace his initial interest in developing a computer to his experience of the Colossus. Newman's intention to build a computer at Manchester is confirmed in numerous documents. We can follow in reasonable detail In Williams' case, the documentary evidence of his interest in developing a storage device for use in a computing machine is incontrovertible but there is nothing, that I am aware of which suggests he had any personal interest in developing a computer at Manchester or elsewhere. He is not called on by the University authorities to report on progress independently of Newman's Royal Society funded project. The evidence for an independent project led by Williams is scant and almost entirely non-documentary. Construing Williams to have been engaged on a rival project requires a great deal of contrary evidence to be set to one side and demands a very partial interpretation to be applied to what remains.

Another ground on which Lavington and others have argued that Williams was engaged on an independent computer project revolves around finances. The two project myth treats as very significant a lack of spending on the development of the Baby out of Royal Society funds. The claim that the Baby enjoyed from the outset significant financial support from TRE in contrast to a complete or almost complete lack of financial assistance from Newman and the Royal Society until after the Baby was complete may be termed the financial myth. Lavington sets out the position in a fairly neutral way:

"The Royal Society grant of $\$ 35,000$ remained substantially intact for several years, eventually providing for the construction of a building to house the University's Ferranti Mark 1 computer in 1951." [11] Brian Napper, although somewhat strident in tone, does make very clear the important role of the financial myth in supporting the two project myth:

"There is no question that the "Baby" was Williams' project not Newman's (and effectively funded by the TRE). The confusion is caused because Newman got a grant of $£ 20000$ capital $+5 * £ 3000$ per year for wages to build a computer from the Royal Society in 1946. Also the room the Baby was built in was called the Royal Society Computing Machine Laboratory. I won't go into the full debate, but in my mind the empirical proof is in the University records, which show that "Royal Society" was stripped from the name after a year or two, and all the capital and the remaining half of the wages in Newman's grant was spent in 1950 on a new building to house the Ferranti Mark I -the 3rd generation of Williams' (and Kilburn's) computers !!” [12] 
There are two substantial defects which run through these accounts. First, they fail correctly to represent how and where the Royal Society Grant was actually spent. Secondly, they take no explicit notice of the details of Newman's bid to the Royal Society or his estimate of expected costs. Thus, the financial myth ignores the financial context. By January 1946, it had been made clear to Newman that while the university approved of his plan to build a computer they were unwilling to provide financial support. Writing to the Royal Society in support of his application on 28th January 1946, Newman gave approximate financial projections, which included provision for $£ 800$ for the salary of an Engineer and $£ 500$ for two "half-time" mathematicians. No detailed breakdown of costs is given for the construction of the machine beyond noting that the total cost would be $£ 10,000$ over the first three years and $£ 20,000$ over the first five years. There is no indication that the project was intended to come to an end after the fifth year and in the light of other comments he makes it seems reasonable to suppose Newman saw Manchester as staying at the forefront of computing over the long term. Newman made no allowance for his own salary presumably because felt he could direct the project in the time he had available after his departmental duties were complete. His managerial style, which as we have seen, involved picking very capable lieutenants and giving them freedom to do their jobs without unnecessary interference, would have made this a realistic expectation. Whereas Newman had expected to spend $£ 1300$ during the first year of the project to cover salaries he ended up needing only $£ 500$. In addition, approximately $£ 300$ was spent on sending Rees to the Moore School lectures. Allowing another $£ 50$ for miscellaneous spending, this would have brought the first year's actual expenditure up to c.£850. TRE's contribution to the project represented a saving against estimates worth some $£ 500$ for Kilburn's salary and a further $£ 100$ (approximately) in donated components. It is difficult to place an firm cash value on the hardware TRE supplied as it was mostly surplus stock which if it had appeared on the open market would have had a serious effect on prices Consequently, it would almost certainly have been destroyed if it had not been given to Manchester14. The department of Electro-Technics contributed some test equipment which they built in-house and a quantity of small consumables from their own stores. Additionally they provided infrastructure e.g., floor space, drawing office facilities, workshop facilities. In total we might nominally value this contribution as being worth $£ 150.15$

During the first year of the project's life Newman spent around $63 \%$ of his estimated budget. The difference between anticipated and actual spending was entirely the result of Kilburn's salary being covered by TRE whose additional generosity in donating components had no further beneficial effect on Newman's first year projections since he hadn't allowed for them in any case. There is no reason to believe that Newman would not have covered Kilburn's wages had the TRE proved reluctant, since he had allowed for such expenditure and had been granted the necessary funds. It is extremely unlikely that the Royal Society, or any other grant awarding body, would have looked kindly on any attempt by Newman to pay Kilburn's salary when alternative funding had unexpectedly appeared. In fact, it should be said that the Royal Society showed great latitude in allowing the $£ 20,000$ originally intended for capital development to be spent post hoc on a building. It is also worth mentioning that had the Royal Society instead clawed back the capital grant, matching funds would have had to be found from the budget supporting further computer development at Manchester. The 
Royal Society can reasonably be thought of as major investors in the development of the machines that followed the SSEM. However, despite the financial scale and political importance of the contribution made by the Royal Society to the SSEM and to its successors, the part it played has received little acknowledgement from historians.

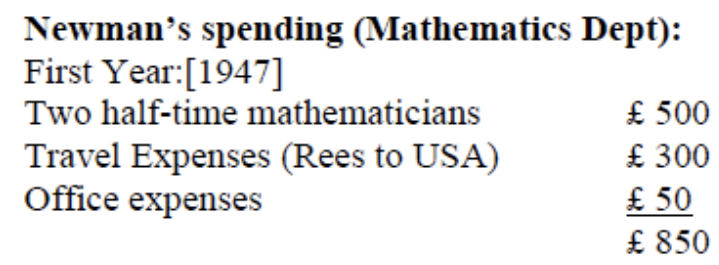

Newman also supplied a huge quantity of components from Bletchley Park (several tons)

TRE spending (estimated):

First Year :[1947]

Kilburn's Salary c£500

Components (nominal value) c£100

Infrastructural support (nominal value) $\underline{c £ 150}$

$\operatorname{c£750}$

\section{Williams' spending (Electro-technics Dept. estimated):}

\section{First Year:[1947]}

Office expenses and lab space

\section{$\underline{\mathrm{c} £ 100}$}

c $£ 100$

In view of the actual spending that took place and the financial context within which Newman was operating, Napper's bald statement of the financial myth, made in the course of commenting on the development of the Baby: "That 'Professor Newman had a grant' was true, but in effect it was not used until it was not required." [13] can be seen to fall very wide of the mark.

\section{Conclusion}

I have covered a substantial amount of ground. Based on a complete re-examination of the available source material, I have provided a new historical interpretation of the development of one of the most iconic machines in the history of British computing. In doing so, I have called into question the dominant historical narrative and set aside an account of the period which has hitherto remained unchallenged. I have identified three persistent myths that have acted to distort the picture of early computing in Britain and argued, I hope persuasively, that they are without foundation.

In showing that the origins of the Manchester Baby lie in the wartime setting of Bletchley Park and that the mathematicians who worked on Colossus were not only 
engaged in a process of knowledge and technology transfer were acting with the full knowledge and authority of the authorities I have cleared the way for historians of computing to consider for the first time the extent to the British government played an active part in fostering and directing technological innovation and development in the immediate aftermath of the war.

\section{References}

1. Hilbert, D., Ackerman, W.: Grundzüge der theoretischen Logik. Springer, Berlin (1928)

2. Davis, M.: Computability and Unsolvability, 3rd edn. Dover, New York (1982)

3. Evans, C.R.: Interview with Maxwell Herman Alexander Newman (Transcript by D.P. Anderson). Science Museum/National Physical Laboratory (1975) (unpublished interview)

4. On computable numbers, with an application to the Entscheidungsproblem. Proceedings of the London Mathematical Society, Ser. 242 (1937)

5. Anderson, D.P.: Was the Manchester 'Baby' conceived at Bletchley Park? BCS eWIC (2008), http: / /www.bcs .org/upload/pdf / ewic_tur04_paper3.pdf

6. Newman, M.H.A.: Letter to Colonel Wallace, D.D.(A), Government Communications Headquarters, Bletchley Park, August 8 (1945) (unpublished letter)

7. Newman, M.H.A.: Letter to John von Neumann. In: Box 6 Folder 2 Item 2 The Newman Digital Archive, the History of Computing Group and St John's College Cambridge, February 8 (1946a) (unpublished letter)

8. Evans, C.R.: Interview with Frederic Calland Williams (Transcript by David P. Anderson). Science Museum/National Physical Laboratory (1976a) (unpublished interview)

9. Evans, C.R.: Interview with Donald Michie (Transcript by David P. Anderson). Science Museum/National Physical Laboratory (1976b) (unpublished interview)

10. Hodges, A.: Alan Turing: The Enigma. Simon \& Shuster, New York (1983)

11. Lavington, S.H.: A History of Manchester Computers, 2nd edn. British Computer Society (1998)

12. Napper, R.B.E.: The Moore School Lectures and the British lead in stored program computer development 1946- 1953 (2004),

http://www.virtualtravelog.net/entries/2003/10/the_moore_sch ool_lectures_and_the_british_lead_in_stored_program_computer _development_1946_1953.html (retrieved December 11, 2005)

13. Napper, R.B.E.: Newman's Contribution to the Mark 1 Machines (1998), http://www. computer50.org/mark1/newman.html (retrieved December 6, 2005) 